\title{
Social media platforms: a primer for researchers
}

\author{
Olena Zimba ${ }^{10}$, Armen Yuri Gasparyan² ${ }^{\text {ID }}$ \\ ${ }^{1}$ Department of Internal Medicine No. 2, Danylo Halytsky Lviv National Medical University, Lviv, Ukraine \\ 2Departments of Rheumatology and Research and Development, Dudley Group NHS Foundation Trust (Teaching Trust of the \\ University of Birmingham, UK), Russells Hall Hospital, Dudley, West Midlands, UK
}

\begin{abstract}
Social media platforms play an increasingly important role in research, education, and clinical practice. As an inseparable part of open science, these platforms may increase the visibility of research outputs and facilitate scholarly networking. The editors who ethically moderate Twitter, Facebook, and other popular social media accounts for their journals may engage influential authors in the post-publication communication and expand societal implications of their publications. Several social media aggregators track and generate alternative metrics which can be used by researchers for visualizing trending articles in their fields. More and more publishers showcase their achievements by displaying such metrics along with traditional citations. The Scopus database also tracks both metrics to offer a comprehensive coverage of the indexed articles' impact.

Understanding the advantages and limitations of various social media channels is essential for actively contributing to the post-publication communication, particularly in research-intensive fields such as rheumatology.
\end{abstract}

Key words: social media, periodicals as topic, publication ethics, rheumatology.

\section{Introduction}

Social media platforms are essential for dissemination of information and engagement of scholars in science communication. With upgrades of online tools and the emergence of various digital technologies over the past decade, it has become easier to generate online information and reach scholars worldwide. Various digitized items, including articles, books, images, and videos, have become common objects for knowledge dissemination and professional discussion on specially designed networking sites.

The social media term of the Medical Subject Headings (MeSH), which was introduced in 2012, characterized user-generated content, high degree of interaction, and ease of integration with other sites as the main features of social media platforms (https://www.ncbi. nlm.nih.gov/mesh/68061108). As an example, social media plugins are now available on most journal sites, PubMed, and PubMed Central platforms to aid readers to disseminate article links and attract the attention of the global scholarly community.

Students, researchers, and journal editors are now offered a wide variety of public and closed networking sites for voicing their concerns, learning, and undertaking research. The global market of drugs and medical technologies has also embraced the emerging opportunities to expand their online presence and actively promote various products.

Given the diversity of cultural traditions and predominant languages of scholarly writing, the attitudes toward public engagement and institutional use of social media vary globally [1, 2]. Some countries prioritize their local platforms, selectively use globally popular channels, and block sites which may be used for spreading undesirable and politically incorrect information. As a prime example, WeChat is a popular platform for networking, disseminating information, and building up online presence in China [3]. Some platforms popular in 
Anglophone countries are not used in China for scholarly purposes.

The current COVID-19 pandemic has brought to the fore online channels which are actively employed for microblogging and monitoring pandemic statistics, vaccine development, and global research issues [4] The publishing enterprise has also switched toward online platforms with a potential to increase the quality research output. A recent survey of rheumatologists and other specialists identified quality peer review, open access, and social media promotion as the key factors of impactful publishing [5].

\section{Editorial guidance on social media}

Over the past decade, social media have emerged as essential tools for scholarly activities. Individual users and research groups are now populating their professional niche on various blogs and online channels to evaluate published articles, reveal research misconduct, criticize their colleagues, and initiate self-cleaning, or retraction. As such, and to direct the attention of a relevant audience to online postings and manage post-publication communication, social media should be moderated by professionals with digital skills and understanding of the importance of constructive contributions at preand post-publication stages.

Although recommendations of global editorial associations still lack direct statements on etiquette and appropriate use of social media, there are some points in the updated documents of the International Committee of Medical Journal Editors (ICMJE) and the Committee on Publication Ethics (COPE) that highlight the role of journal editors in unbiased post-publication commenting and offering their readers a possibility to express their ideas and post comments [6, 7].

In line with these points, moderated journal blogs and social media accounts are required to aid publishers in upgrading their editorial policies and increasing the quality of publications. Authors may also actively promote their articles on social media to gain more visibility and contribute to the attractiveness of their target journals for the global scholarly community [8].

While there is no global consensus on social media, publishers and professional societies set their own instructions [9]. Networking, training, and maintaining societal communication are now perceived as the main benefits of online platforms in rheumatology that should be nurtured and ethically moderated [10].

Experts predict the growing importance of social media for rheumatology journals and suggest engaging in post-publication promotion more editors with digital skills and proper understanding of ethical norms and cultural differences [11]. A recent survey of rheumatolo- gy authors $(n=102)$ revealed a positive attitude of over two-thirds of respondents toward promotion of their articles on ResearchGate, Twitter, and Facebook [12]. Nearly half of the surveyees proposed to entrust post-publication promotion to editors with skills in designing graphical abstracts and operating with hashtags. Such editors with impressive track records on social media are increasingly recognized as the key figures in the publishing enterprise [13].

Contributions of social media editors are crucial in the time of the COVID-19 pandemic when distinguishing fact from fiction is a matter of professional performance, ethical stance, and influence on safe healthcare $[14,15]$.

\section{Social media platforms for scholarly activities}

There are numerous online sites which can be employed by researchers, educators, and journal editors for disseminating scientific information, promoting articles, and analyzing the so-called societal impact (Table I). Various sites attract users with diverse interests and aims to share specific graphical and textual materials [16].

In the pre-pandemic period, higher education students were mainly relying on Facebook and Twitter for improving their language skills, undertaking research, and building up academic profiles that, on average, took 10-60 minutes daily [17]. A pre-pandemic analysis of online platforms in medical education pointed to blogs, wikis, Twitter, and Facebook postings as the main tools for engaging learners in an online environment and microblogging and essay writing as expected outcomes of social media activities [18]. A survey of 233 young rheumatologists, which was organized by the Emerging EULAR Network (EMEUNET), distinguished Facebook as the dominant platform of communication and processing news notes, clinical, and research updates for $91 \%$ of respondents [19].

The COVID-19 pandemic has brought new challenges for medical education, and prioritized platforms for videoconferencing such as Zoom [20]. Videoconferencing has become particularly useful for rheumatology education [21].

The quality, volume, and language of shared materials vary widely across social media. The users with advanced English skills, particularly those in Anglophone countries, are at an advantage as they benefit greatly from online learning and active contribution to the communication on popular channels such as Twitter [22]. Researcher and author activities on several blogs and social networking sites maximize their visibility and the impact of scholarly articles [23]. 
Table I. Examples of social media platforms for scholarly activities

\begin{tabular}{|c|c|c|}
\hline Platforms & Advantages & Limitations \\
\hline $\begin{array}{l}\text { Twitter } \\
\text { https://twitter.com/ }\end{array}$ & $\begin{array}{l}\text { It is the largest microblogging platform where users } \\
\text { generate tweets, retweet, and like postings. } \\
\text { The use of hashtags and Twitter handles increases } \\
\text { the engagement of the account holders. Photo- and } \\
\text { video-sharing services make the platform attrac- } \\
\text { tive for education and live streaming of meetings. } \\
\text { Editors may moderate their journal accounts for } \\
\text { boosting the immediate impact of publications }\end{array}$ & $\begin{array}{l}\text { Limited number of characters } \\
\text { in a tweet (280), numerous Twitter } \\
\text { bots with indiscriminate automatic } \\
\text { posts, limited use in non-Anglophone } \\
\text { countries }\end{array}$ \\
\hline $\begin{array}{l}\text { Facebook } \\
\text { https://www.facebook.com/ }\end{array}$ & $\begin{array}{c}\text { Globally popular, actively used for live streaming } \\
\text { meetings, and interconnecting with Zoom, YouTube, } \\
\text { and other video-sharing sites }\end{array}$ & $\begin{array}{l}\text { Mostly used for personal and friendly } \\
\text { communications, low weight } \\
\text { in terms of alternative metrics }\end{array}$ \\
\hline $\begin{array}{l}\text { Instagram } \\
\text { https://www.instagram.com/ }\end{array}$ & $\begin{array}{l}\text { This platform is employed for sharing photos, } \\
\text { medical images, and videos. Journals that predomi- } \\
\text { nantly publish images may benefit from their active } \\
\text { presence on this site }\end{array}$ & $\begin{array}{l}\text { No weight for altmetric aggregate } \\
\text { score calculation, small number } \\
\text { of journals with Instagram accounts }\end{array}$ \\
\hline $\begin{array}{l}\text { YouTube } \\
\text { https://www.youtube.com/ }\end{array}$ & $\begin{array}{l}\text { This is an online video-sharing platform with a varie- } \\
\text { ty of services for educators, researchers, and editors } \\
\text { and navigation to many other online channels. } \\
\text { Online meetings can be live streamed and archived } \\
\text { on this site }\end{array}$ & $\begin{array}{l}\text { Reliability and quality of posted } \\
\text { videos vary widely. Some videos } \\
\text { are promotional, misleading, and } \\
\text { damaging for patient health }\end{array}$ \\
\hline $\begin{array}{l}\text { Linkedln } \\
\text { https://www.linkedin.com/ }\end{array}$ & $\begin{array}{l}\text { It can be used for professional networking, career } \\
\text { development, and job advertisements. Journals may } \\
\text { set their accounts on this site to expand their reach } \\
\text { to potential staff members }\end{array}$ & $\begin{array}{l}\text { No weight for altmetric aggregate } \\
\text { score calculation }\end{array}$ \\
\hline $\begin{array}{l}\text { Mendeley } \\
\text { https://www.mendeley.com/ }\end{array}$ & $\begin{array}{l}\text { Researchers use Mendeley bookmarking and } \\
\text { reference management tools for building up personal } \\
\text { libraries. This site can aid in evaluating collabora- } \\
\text { tors' profiles. An analysis of bookmarking activities } \\
\text { reveals interested users/scholars }\end{array}$ & $\begin{array}{l}\text { Not included in altmetric aggregate } \\
\text { score calculation }\end{array}$ \\
\hline $\begin{array}{l}\text { ResearchGate } \\
\text { https://www.researchgate.net/ }\end{array}$ & $\begin{array}{c}\text { This site is used for open archiving, networking, } \\
\text { evaluating collaborators' profiles, and discussing } \\
\text { scientific issues }\end{array}$ & $\begin{array}{l}\text { The quality of archived materials } \\
\text { is not reviewed, and the displayed } \\
\text { author-level metric ("RG Score") is } \\
\text { unacceptable for scholarly evaluation }\end{array}$ \\
\hline
\end{tabular}

\section{Social media metrics}

Societal attention surrounding scholarly publications is currently tracked and measured by several aggregators of alternative metrics, or altmetrics, which process information in news outlets, blogs, and various networking and scholarly evaluation sites such as F1000, Publons, and PubPeer. The aggregated information and resultant scores change in real time, reflecting societal attention trends and complementing traditional citation metrics [24].

There are three widely known companies that aggregate social media attention and complement citation metrics with snapshot altmetrics reports: Altmetric.com (https://www.altmetric.com/), Plum Analytics (PlumX; https://plumanalytics.com/) and Our Research (formerly known as ImpactStory; https://our-research.org/). Altmetric.com and PlumX reports may vary due to the differing counting of the same data sources and prioritized extraction of information from blogs, news outlets, and tweets by the former and Mendeley by the latter [25].

Some publishers currently showcase the influence of their articles by displaying the Altmetric Attention Scores (AAS) and the donut rings generated by Altmetric.com. The AAS are calculated using an automated algorithm. This algorithm weighs high references in news outlets, blogs, policy documents, patents, and Wikipedia. Tweets and retweets are weighed less but often outnumber other social media activities. Processed from publicly moderated accounts, Facebook mentions weigh less than tweets [26].

Publishers and journal editors alike may adjust their editorial strategies in line with the trending articles, reports and other services offered by Altmetric.com. Researchers, in turn, may process the AAS to visualize the most influential articles and explore the most active post-publication promotion channels in their fields [27]. Finally, Scopus (Elsevier) indexing services process and 
display altmetric information from PlumX which is reflected in variably sized and colored Plum Print circles [28].

\section{Social media ethics}

The scarcity of instructions and ethics statements is partly responsible for unethical postings of images, texts, and promotion leaflets of drugs across social media. Separating personal and business accounts is the main strategy to minimize undesirable consequences of conflicting social media activities [9]. Personal photos, videos, and family communications should not appear on accounts intended for professional knowledge transfer and cooperation of society fellows. Business, or scholarly, accounts require their own sets of regulations and filtering by skilled moderators. While numerous journal accounts are increasingly occupying social media, it is expected that their instructions will soon include recommendations on editors' and authors' appropriate promotion activities.

Currently, there are only a few sets of ethics guidelines that regulate activities across academic disciplines with extensive social media presence such as dermatology and pathology. Protecting patient privacy and avoiding dissemination of sensitive and identifying images are central to maintaining professionalism on social media [29].

Social media editors should adhere to their publisher regulations and avoid re-posts of images with unmasked identities, even if such items are available from reputable journals. The Association of State and Provincial Psychology Boards (USA) issued its statements on appropriate use of social media in psychology practice and emphasized confidentiality, informed consent, risk management, competence of users, and avoidance of overlapping professional and personal activities, among other regulatory acts [30]. These statements can be adapted and enforced by editors of most clinical disciplines.

Filtering information and promoting reliable graphical and textual materials are warranted in the time of the COVID-19 pandemic since postings on drugs with no supporting evidence may have dire consequences [31].

\section{Conclusions}

The open science movement and COVID-19 pandemic have made it urgent to employ reliable online channels for education, research, and practice [14, 32]. Some social media platforms have emerged as essential for scholarly communication and societal impact measurement. Of these, Twitter is perhaps the most popular channel with an immediate influence on post-publication promotion of most scholarly articles. Digital skills and awareness of the advantages and limitations of
Twitter and other popular platforms may help stakeholders of science communication to effectively contribute to the global growth of science.

Research-intensive disciplines such as rheumatology may benefit greatly from establishing globally visible social media accounts and expanding networks of engaged scholars [33]. By actively disseminating information on Twitter, Instagram, and Facebook, rheumatologists may instantly reach and maintain ties with different user groups such as patients, students, and researchers. A recent EMEUNET survey of 233 rheumatologists demonstrated that more than half of respondents preferred Facebook for developing collaborations and Twitter for journal club meetings [34].

The role of digital editors is increasingly important for moderating social media accounts and preventing unethical activities. Researchers, students, and educators should also be trained to professionally contribute to the social media discussions and ethically promote scholarly items [35]. Guidelines are warranted to improve the quality of social media activities and increase the visibility of influential research outputs.

The authors declare no conflict of interest.

\section{References}

1. Syrkiewicz-Świtała M, Romaniuk P, Strzelecka A, et al. Prospects for the Use of Social Media Marketing Instruments in Health Promotion by Polish Marshal Offices. Front Public Health 2018; 6: 65, DOI: 10.3389/fpubh.2018.00065.

2. Zeng R, Li M. Social Media Use for Health Communication by the CDC in Mainland China: National Survey Study 2009-2020. J Med Internet Res 2020; 22: e19470, DOI: 10.2196/19470.

3. Lien $\mathrm{CH}$, Cao Y. Examining WeChat users' motivations, trust, attitudes, and positive word-of-mouth: Evidence from China. Comput Hum Behav 2014; 41: 104-111, DOI: 10.1016/j.chb. 2014.08.013.

4. Wang J, Zhou Y, Zhang W, et al. Concerns Expressed by Chinese Social Media Users During the COVID-19 Pandemic: Content Analysis of Sina Weibo Microblogging Data. J Med Internet Res 2020; 22: e22152, DOI: 10.2196/22152.

5. Gupta L, Gasparyan AY, Zimba O, Misra DP. Scholarly publishing and journal targeting in the time of the Coronavirus Disease 2019 (COVID-19) pandemic: a cross-sectional survey of rheumatologists and other specialists. Rheumatol Int 2020; 40: 2023-2030, DOI: 10.1007/s00296-020-04718-x.

6. Recommendations for the Conduct, Reporting, Editing, and Publication of Scholarly Work in Medical Journals. Updated December 2019. Available from: http://www.icmje.org/icmje-recommendations.pdf [Accessed: 20.12.2020].

7. Core practices. Available from: https://publicationethics.org/ core-practices [Accessed: 20.12.2020].

8. Mašić I, Begić E, Donev DM, et al. Sarajevo Declaration on Integrity and Visibility of Scholarly Publications. Croat Med J 2016; 57: 527-529, DOI: 10.3325/cmj.2016.57.527. 
9. Zimba O, Radchenko O, Strilchuk L. Social media for research, education and practice in rheumatology. Rheumatol Int 2020; 40: 183-190, DOI: 10.1007/s00296-019-04493-4.

10. Berenbaum F. The social (media) side to rheumatology. Nat Rev Rheumatol 2014; 10: 314-318, DOI: 10.1038/nrrheum.2014.20.

11. Pineda C, Pérez-Neri I, Sandoval H. Challenges for social media editors in rheumatology journals: an outlook. Clin Rheumatol 2019; 38: 1785-1789, DOI: 10.1007/s10067-019-04586-2.

12. Haldule S, Davalbhakta S, Agarwal V, et al. Post-publication promotion in rheumatology: a survey focusing on social media. Rheumatol Int 2020; 40: 1865-1872, DOI: 10.1007/s00296020-04700-7.

13. Lopez M, Chan TM, Thoma B, et al. The Social Media Editor at Medical Journals: Responsibilities, Goals, Barriers, and Facilitators. Acad Med 2019; 94: 701-707, DOI: 10.1097/ACM. 0000000000002496.

14. Gasparyan AY, Zimba O, Misra DP, Kitas GD. Monitoring Information Flow on Coronavirus Disease 2019 (COVID-19). Mediterr J Rheumatol 2020; 31(Suppl 2): 243-246, DOI: 10.31138/ mjr.31.3.243.

15. Ball P, Maxmen A. The epic battle against coronavirus misinformation and conspiracy theories. Nature 2020; 581(7809): 371-374, DOI: 10.1038/d41586-020-01452-z.

16. Ahmed S, Gupta L. Social media for medical journals. Cent Asian J Med Hypotheses Ethics 2020; 1: 26-32, DOI: 10.47316/ cajmhe.2020.1.1.04.

17. Zachos G, Paraskevopoulou-Kollia E-A, Anagnostopoulos I. Social Media Use in Higher Education: A Review. Educ Sci 2018 8: 194, DOI: 10.3390/educsci8040194.

18. Cheston CC, Flickinger TE, Chisolm MS. Social media use in medical education: a systematic review. Acad Med 2013; 88 893-901, DOI: 10.1097/ACM.0b013e31828ffc23.

19. Nikiphorou E, Studenic P, Ammitzbøll CG, et al. Social media use among young rheumatologists and basic scientists: results of an international survey by the Emerging EULAR Network (EMEUNET). Ann Rheum Dis 2017; 76: 712-715, DOI: 10.1136/ annrheumdis-2016-209718.

20. Dedeilia A, Sotiropoulos MG, Hanrahan JG, et al. Medical and Surgical Education Challenges and Innovations in the COVID-19 Era: A Systematic Review. In Vivo 2020; 34 (3 Suppl): 1603-1611, DOI: 10.21873/invivo.11950.

21. Koumpouras F, Helfgott S. Stand Together and Deliver: Challenges and Opportunities for Rheumatology Education During the COVID-19 Pandemic. Arthritis Rheumatol 2020; 72: 10641066, DOI: 10.1002/art.41278.

22. Sterling M, Leung P, Wright D, Bishop TF. The Use of Socia Media in Graduate Medical Education: A Systematic Review. Acad Med 2017; 92: 1043-1056, DOI: 10.1097/ACM.000000 0000001617.
23. Hoang JK, McCall J, Dixon AF, et al. Using Social Media to Share Your Radiology Research: How Effective Is a Blog Post? J Am Coll Radiol 2015; 12: 760-765, DOI: 10.1016/j.jacr.2015.03.048.

24. Nuzzolese AG, Ciancarini P, Gangemi A, et al. Do altmetrics work for assessing research quality? Scientometrics 2019; 118: 539-562, DOI: 10.1007/s11192-018-2988-z.

25. Ortega JL. Reliability and accuracy of altmetric providers: a comparison among Altmetric.com, PlumX and Crossref Event Data. Scientometrics 2018; 116: 2123-2138, DOI: 10.1007/ s11192-0182838-z.

26. How is the Altmetric Attention Score calculated? Available from: https://help.altmetric.com/support/solutions/articles/ 6000060969-how-is-the-altmetric-attention-score-calculated [Accessed: 20.12.2020].

27. Sugimoto CR, Work S, Larivière V, Haustein S. Scholarly use of social media and altmetrics: A review of the literature. J Assoc Inf Sci Technol 2017; 68: 2037-2062, DOI: 10.1002/asi.23833.

28. PlumX Metrics now on Scopus: Discover how others interact with your research. Available from: https://blog.scopus.com/ posts/plumx-metrics-now-on-scopus-discover-how-others-interact-with-your-research [Accessed: 20.12.2020].

29. Crane GM, Gardner JM. Pathology Image-Sharing on Social Media: Recommendations for Protecting Privacy While Motivating Education. AMA J Ethics 2016; 18: 817-825, DOI: 10.1001/journalofethics.2016.18.8.stas1-1608.

30. Drude K, Messer-Engel K. The Development of Social Media Guidelines for Psychologists and for Regulatory Use. J Technol Behav Sci 2020; 1-9, DOI: 10.1007/s41347-020-00176-1 [Online ahead of print].

31. Lima DL, Lopes MAAAM, Brito AM. Social media: friend or foe in the COVID-19 pandemic? Clinics (Sao Paulo) 2020; 75: e1953, DOI: 10.6061/clinics/2020/e1953.

32. Gasparyan AY, Yessirkepov M, Voronov AA, et al. Comprehensive Approach to Open Access Publishing: Platforms and Tools. J Korean Med Sci 2019; 34: e184, DOI: 10.3346/jkms.2019.34. e184.

33. Krusche M, Burmester GR, Knitza J. Digital crowdsourcing: unleashing its power in rheumatology. Ann Rheum Dis 2020; 79: 1139-1140, DOI: 10.1136/annrheumdis-2020-217697.

34. Najm A, Kostine M, Pauling JD, et al. Multidisciplinary collaboration among young specialists: results of an international survey by the emerging EULAR network and other young organisations. RMD Open 2020; 6: e001398, DOI: 10.1136/rmdopen-2020-001398.

35. Dua AB, Kilian A, Grainger R, et al. Challenges, collaboration, and innovation in rheumatology education during the COVID-19 pandemic: leveraging new ways to teach. Clin Rheumatol 2020; 39: 3535-3541, DOI: 10.1007/s10067-02005449-x. 